\title{
Assessment of conventional and non-conventional estimation of live weight, carcass characteristics and dressing percentage of Nigerian breeds of goats as panacea for livestock entrepreneurship
}

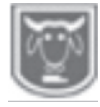

Abstract

Ajayi, M. O., Osowe, C. O. and Babayemi, O. J.

Department of Animal Science, University of Ibadan, Nigeria

*Author for correspondence: moajayi5@gmail.com

The price tag on goat at the farm gate or market is usually by visual appraisal as the use of weighing scale for body weight determination is cumbersome and technical. This study was carried out to determine the reliability of using the girth tape as a non-conventional method of live weight, carcass characteristics and dressing percentage estimation for economic gain of goats. Female goats $(n=75)$ were purchased from Akinyele goat market to comprise of WAD $(n=25)$, Sahel $(n=25)$ and Maradi $(n=25)$ with the age range of 22-24 months. The weights were measured using a conventional weighing scale. Also, a calibrated girth tape was used to measure the heart girth of the circumference of the chest. The goats were humanely slaughtered and properly processed for the determination of dressing percentage. The carcasses were carefully sectioned into five parts namely: neck, right forearm, left forearm, right thigh and left thigh and the weights were determined. The values for scale and girth tape measurements were $15.90 \pm 4.15 \mathrm{~kg}$ and $16.28 \pm 4.17 \mathrm{~kg}, 20.81 \pm 5.80 \mathrm{~kg}$ and $19.97 \pm 5.56 \mathrm{~kg}$, and $25.47 \pm 3.70 \mathrm{~kg}$ and $25.20 \pm 3.48 \mathrm{~kg}$, respectively. There were not significant $(p>0.05)$ differences between scale and girth tape measurements for the goats. The dressing percentages were $51.29 \pm 3.87 \%, 49.26 \pm 3.51 \%$ and $43.11 \pm 4.17 \%$ for WAD, Maradi and Sahel goats, respectively. There were apparent $(p<0.05)$ differences in the dressing percentage among the breeds. There were significant $(p<0.05)$ variations in the neck $(0.87-1.21 \mathrm{~kg})$, right thigh $(1.09-1.50 \mathrm{~kg})$, left thigh $(1.85-2.42 \mathrm{~kg})$, right forearm $(1.79$ $2.45 \mathrm{~kg})$ and left forearm $(1.82-2.39 \mathrm{~kg})$ among the breeds. There were significant differences in the weights of liver (0.41-0.51g) and kidney (0.11-0.15g) but none for heart and lungs among the three breeds of goats. There was also significant $(p<0.05)$ difference in the weights of liver and kidney $(0.51 \pm 0.12 \mathrm{~g})$ for Sahel goats. The results of the coefficients of correlation between weighing scale and girth tape measurements of body weights of goats were significant, positive and high. The result of the regression analysis showed an adjusted $R^{2}$ of 0.992. It can be concluded that the girth tape may be a reliable tool without weighing scale while the WAD goats may also be more economical to slaughter for sales as it yielded more meat than Maradi and Sahel goats.

Keywords: Estimation, Conventional, Non-conventional, Girth tape, Dressing percentage

\section{Introduction}

Goat production, marketing and distribution to the ultimate consumers in Nigeria are by no means very small. The price tag on goat at the farm gate or market to the end users is usually by visual appraisal. Eye assessment before placing the monetary value on the desired goats can be deceptive as it depends entirely on the bargaining power of the parties involved in the negotiation. This is due to the lack of standard weighing scale for the livestock farmers and in the various livestock markets for concise live body weight measurement. In other parts of the world, purchase of livestock at all level is done with the use of weighing scale that are often location and type specific. Slippers et al. 
Assessment of conventional and non-conventional estimation of live weight, carcass characteristics and the dressing percentage of Nigerian breeds of goats

(2000) reported that knowing the live weight of small ruminants is important for reasons of breeding, correct feeding, health as well as for appropriate price determination for animals on hoof.

However, there are many factors that may militate against the use of weighing scale in Nigeria, including unavailability and its spare parts when spoilt, lack of technicalknow-how to operate and the logistics of carrying such heavy and sensitive equipment all about. If goat business must thrive in Nigeria, there should be other means of ensuring the relative accurate weights before making an effective demand. In this regard, non-conventional method for animal body measurement may be a way forward. Fajemilehin and Salako (2008) suggested that a study of linear body measurements on most farms animals in the tropics is important because most farmers lack weighing scales and the education to understand how to operate and apply them to marketing of the stocks. Linear body measurements can therefore, be used as a way of estimating weight and market value in terms of cost of the animals and returns expected from saleable parts. One of the smallest and portable instruments can be used is the girth tape for body linear measurements. McGregor (2007) reported that girth tapes are designed for the purpose of estimating live weight of animals provided that they have been calibrated for goats. According to Macdonald et al. (2009), a girth tape is developed specifically for buffalo and cattle in Lao Peoples Democratic Republic to empower farmers with knowledge on the value of their animals (by weight for trading) and to improve their management which in turn improves the welfare of the livestock and the economic standing of subsistence farmers. In the recent times, a more specific girth tape has been developed and calibrated for goats. Thus, a conventional and non-conventional estimation of live weight and the dressing percentage of Nigerian breeds of goats as panacea for livestock entrepreneurship were assessed.

\section{Materials and methods \\ Location and experimental animals}

The research was carried out at the Slaughter House, University of Ibadan. Ibadan is located within the south-western part of Nigeria on latitude $07^{\circ} 22^{1} \mathrm{~N}$ and longitude $03^{\circ} 58^{1} \mathrm{E}$ with a mean altitude of $273 \mathrm{~m}$ above sea level. This area has an annual rainfall of $1420.06 \mathrm{~mm}$ per annum with two peak period in June and September. It has a mean maximum temperature of $26.46^{\circ} \mathrm{C}$, mean minimum temperature of $21.42^{\circ} \mathrm{C}$ and average relative humidity of $74.55 \%$.

The research work was carried out over a period of se ven month s (February-August), which was at the late dry season and mid wet season. The three predominant breeds of goats (West African dwarf, Maradi and Sahel) of different ages and weights were sourced from different local markets in Oyo, Kwara and Niger States. A total of 75 goats included 25 goats each of the different breeds were purposively selected and purchased for the study. The process for the selection targeted market abundance and healthy looking goats. The average age of goats used for this study was between $22-24$ months, using dentition for screening. Seemed and confirmed pregnant goats were excluded from the study.

Determination of live weight using weighing scale and girth tape

Goats were rested sufficiently prior to slaughtering to reduce the extent of the gut fill. Girth tape was then used to estimate the live weight prior to slaughtering. The heart 


\section{Ajayi, Osowe and Babayemi}

girth was taken by the measurement of the circumference of the chest with the girth tape. Since, the tape is calibrated in pounds and or kilogram; the weight was where the lower end met with the other side. The conventional weighing sensitive scale was also used to measure the weight of the goats.

\section{Slaughtering and processing of goats}

Prior to the slaughtering process, the goats were fasted for 20 hours with free access to water and slaughtered according to the local method by severing the jugular vein and the carotid arteries. The goats were humanely slaughtered and proper exsanguination was allowed to enhance the quality of the meat. The goats were drooped in a head down position till the blood was properly drained. The slaughter weights of the goats were taken with the aid of a digital hanging scale. Scalding process was used by scrapping the hair from the skin using boiling water until the carcass was clean as described (Fasae et al., 2011). The abdomen was opened and the internal organs included liver, heart, lungs and kidneys were removed and weighed. The carcasses were carefully sectioned into five parts namely: neck, right forearm, left forearm, right thigh and left thigh weighed and recorded.

Dressing percentage was obtained as carcass weight by a percentage of live weight. Carcass weight was estimated by multiplying live weight by dressing percentage. It was expressed mathematically as: Dressing percentage $=$ (carcass weight $\div$ live weight $) \times 100$

Carcass weight $=$ live weight $\times$ dressing percentage

\section{Data collection and statistical analysis}

Data collected were analyzed using the analysis of variance procedure (Francisco de, 2016). Significant means were separated using the Duncan Multiple Range Test. The relationship of linear measurement parameters and dressing percentage were estimated using Pearson correlation. Regression analysis was used to determine the level of dependence of girth weight, slaughter weight and empty body weight on live weight.

\section{Results and discussion}

The results for the scale and girth tape measurements for live weight determination of three breeds of the goats are in Table 1 . The range value of goats' weights for weighing scale and girth tape were 15.90 and $16.78 \mathrm{~kg}, 19.97$ and $20.81 \mathrm{~kg}$, and 25.20 and $25.47 \mathrm{~kg}$ for WAD, Maradi and Sahel, respectively. The statistical interpretation showed that there were non-significant differences between the use of scale and the girth tape. This implies that any of the two materials can be used to take the live weight of goats anywhere it is available. There are many advantages of the use of girth tape, being portable, less strenuous to operate and may not be subjective to the error of parallax. According to Greenwood et al. (1993), small scale animal producers can utilise girth tape measurements which correlate well with live weight.

Table 2 presents slaughter, full-gut, empty body and carcass weights, and dressing percentage of WAD, Maradi and Sahel breeds of goats in Nigeria. It revealed that slaughter weight, full-gut, empty body weight and dressing percentage showed significant $(p<0.05)$ differences among the breeds. In all the parameters, the trend was such that Sahel $>$ Maradi $>$ WAD goats except for the dressing percentage where WAD was outstandingly better than other breeds. The differences observed could be due to the variation in the breeds as they possess different body conformation. The value of $51.29 \%$ obtained as the dressing percentage for WAD is in accordance with the value of $50-51 \%$ reported by Ukanwoko and Onuoha (2011) for WAD goats and values of 50- 
$52.6 \%$ reported by Ahamefule (2005) for same goats. The remarkable differences among the WAD, Maradi and Sahel breeds of goats in the present study corroborate the report of Dhanda et al. (2003) and Sebsibe et al. (2007) who studied three Ethiopian breeds of goats and observed that breed had an apparent effects on the carcass parameters, dressing percentage and some non-carcass components. It was also reported that breed differences influenced the gut fill at slaughter. The level of gut fill which significantly reduced the dressing percentage in Sahel goat agrees with the findings of Talton (2011) and McGregor (2012) who reported that the higher the gut fill, the lower the dressing percentage.

The average weight of carcass cuts of three breeds of the goats in Nigeria is represented in Table 3. The values ( $\mathrm{kg}$ ) obtained for the three breeds ranged between 0.87 and 1.21 , 1.09 and $1.17,1.8$ and $2.39,1.85$ and 2.42 , 1.79 and $2.45,1.82$ and $2.39,0.47$ and 0.89 for neck, head, right thigh, left thigh, right forearm, left forearm, and shank, respectively. Significant differences $(p<0.05)$ were observed in the values obtained for the neck, head and shank in Sahel being the highest as compared to Maradi and WAD breeds. For all these different cuts of interest, Sahel breed appeared better though it was not necessarily translated to higher economic benefit because of its low dressing percentage earlier discussed in the present study. Never (2015) reported that carcass weight is a major factor affecting the composition of the carcass and is closely related to age at slaughter.

Yield of visceral organs of three breeds of goat is presented in Table 4. The values for the three breeds ranged from $0.41-0.51 \mathrm{~kg}$, $0.12-0.15 \mathrm{~kg}, \quad 0.150 .17-0.31-0.33 \mathrm{~kg}$ for liver, kidney, heart and lung, respectively. Significant $(p<0.05)$ differences in the weight of liver were observed among the breeds but higher in Sahel and WAD. The average weight of the liver, lung and heart from this study is comparable to the value of $1.0 \mathrm{~kg}$ liver weigh reported by McGregor (2007). Kalc et al. (2012) established that kids of greater slaughter weight had greater carcass weight and greater weight of internal organs than kids of smaller slaughter weight. The study at present showed that Sahel goat with the highest body weight also showed significantly higher liver and kidney weights.

The correlation coefficients of organs to the dressing percentage as shown in Table 5 revealed that there were significant and positive correlations between dressing percentage and liver of WAD $(0.4219 \mathrm{~g})$ and Sahel $(0.5011 \mathrm{~g})$ as well as with the kidneys of Sahel $(0.4094 \mathrm{~g})$. The correlation coefficients between dressing percentage with heart and lungs though positive, were not significant $(p>0.05)$. This is essentially true for WAD and Sahel goats. Maradi with higher live weight than WAD goats possessed smaller organ weight in relation to body weight. This could be as a result of its genetic makeup.

Table 1: Scale and girth tape measurements for live weight determination of three breeds of goat in Nigeria

\begin{tabular}{llll}
\hline Parameters & \multicolumn{3}{l}{ Breeds of goats } \\
\cline { 2 - 4 } & WAD & Maradi & Sahel \\
\hline Weighing scale $(\mathrm{kg})$ & $15.90 \pm 4.12$ & $19.97 \pm 5.64$ & $25.20 \pm 3.55$ \\
Girth tape $(\mathrm{kg})$ & $16.28 \pm 4.17$ & $20.81 \pm 5.80$ & $25.47 \pm 3.69$ \\
SEM & 0.583 & 0.788 & 0.50 \\
\hline
\end{tabular}


Ajayi, Osowe and Babayemi

Table 2: Effects of breeds on slaughter, full -gut, empty body and carcass weights, and dressing percentage of some goats in Nigeria

\begin{tabular}{lllll}
\hline Parameters & \multicolumn{2}{l}{} & SEM \\
\cline { 2 - 4 } & WAD & Maradi & Sahel & \\
\hline Slaughter weight $(\mathrm{kg})$ & $14.73^{\mathrm{c}} \pm 4.05$ & $18.93^{\mathrm{b}} \pm 5.29$ & $23.32^{\mathrm{a}} \pm 3.47$ & 0.64 \\
Weight of full gut $(\mathrm{kg})$ & $2.86^{\mathrm{b}} \pm 0.76$ & $3.20^{\mathrm{b}} \pm 0.96$ & $5.03^{\mathrm{a}} \pm 1.53$ & 0.17 \\
Empty body weight $(\mathrm{kg})$ & $11.87^{\mathrm{c}} \pm 3.91$ & $15.73^{\mathrm{b}} \pm 4.75$ & $18.29^{\mathrm{a}} \pm 3.00$ & 0.55 \\
Carcass weight $(\mathrm{kg})$ & $8.03^{\mathrm{b}} \pm 2.24$ & $9.43^{\mathrm{b}} \pm 2.57$ & $11.12^{\mathrm{a}} \pm 1.74$ & 0.28 \\
Dressing percentage (\%) & $51.29^{\mathrm{a}} \pm 3.87$ & $49.26^{\mathrm{a}} \pm 3.51$ & $43.11^{\mathrm{b}} \pm 4.17$ & 0.59 \\
\hline
\end{tabular}

abc Mean with the same superscript do not differ statistically

Table 3: Carcass cuts of three breeds of goats in Nigeria

\begin{tabular}{lllll}
\hline \multirow{2}{*}{ Parameters } & \multicolumn{3}{c}{ Breeds of goats } \\
\cline { 2 - 5 } & & WAD & Maradi & Sahel \\
\hline Neck (kg) & $0.87^{\mathrm{b}} \pm 0.28$ & $0.96^{\mathrm{b}} \pm 0.22$ & $1.21^{\mathrm{a}} \pm 0.28$ & 0.03 \\
Head (kg) & $1.09^{\mathrm{b}} \pm 0.23$ & $1.17^{\mathrm{b}} \pm 0.19$ & $1.50^{\mathrm{a}} \pm 0.16$ & 0.03 \\
Right thigh (kg) & $1.84^{\mathrm{b}} \pm 0.45$ & $2.26^{\mathrm{a}} \pm 0.64$ & $2.39^{\mathrm{a}} \pm 0.50$ & 0.07 \\
Left thigh (kg) & $1.85^{\mathrm{c}} \pm 0.50$ & $2.15^{\mathrm{b}} \pm 0.55$ & $2.42^{\mathrm{a}} \pm 0.44$ & 0.06 \\
Right forearm (kg) & $1.79^{\mathrm{c}} \pm 0.55$ & $2.14^{\mathrm{b}} \pm 0.60$ & $2.45^{\mathrm{a}} \pm 0.44$ & 0.07 \\
Left forearm (kg) & $1.82^{\mathrm{b}} \pm 0.60$ & $2.26^{\mathrm{a}} \pm 0.68$ & $2.39^{\mathrm{a}} \pm 0.38$ & 0.07 \\
Shank (kg) & $0.47^{\mathrm{b}} \pm 0.12$ & $0.54^{\mathrm{b}} \pm 0.09$ & $0.89^{\mathrm{a}} \pm 0.14$ & 0.03 \\
\hline
\end{tabular}

${ }^{a b c}$ Mean with the same superscript do not differ statistically

Table 4: Yield of some organs of three breeds of goat in Nigeria

\begin{tabular}{lllll}
\hline Organ & WAD & Maradi & Sahel & SEM \\
\hline Liver $(\mathrm{g})$ & $0.41^{\mathrm{b}} \pm 0.13$ & $0.46^{\mathrm{ab}} \pm 0.15$ & $0.51^{\mathrm{a}} \pm 0.12$ & 0.015 \\
Kidney (g) & $0.12^{\mathrm{b}} \pm 0.04$ & $0.11^{\mathrm{b}} \pm 0.03$ & $0.15^{\mathrm{a}} \pm 0.03$ & 0.005 \\
Heart $(\mathrm{g})$ & $0.15 \pm 0.07$ & $0.15 \pm 0.07$ & $0.17 \pm 0.07$ & 0.008 \\
Lungs $(\mathrm{g})$ & $0.33 \pm 0.11$ & $0.31 \pm 0.10$ & $0.33 \pm 0.11$ & 0.01 \\
\hline
\end{tabular}

${ }^{a b c}$ Mean with the same superscript do not differ statistically

Table 5: Correlation coefficients between dressing percentage and organs of three breeds of goat

\begin{tabular}{llll}
\hline Parameters & WAD & Maradi & Sahel \\
\hline Liver $(\mathrm{g})$ & $0.4219^{*}$ & $0.1574^{\mathrm{ns}}$ & $0.5011^{*}$ \\
Kidneys $(\mathrm{g})$ & $-0.0456^{\mathrm{ns}}$ & $-0.1689^{\mathrm{ns}}$ & $0.4094^{*}$ \\
Heart $(\mathrm{g})$ & $0.2213^{\mathrm{ns}}$ & $0.3242^{\mathrm{ns}}$ & $0.3591^{\mathrm{ns}}$ \\
Lungs $(\mathrm{g})$ & $0.3545^{\mathrm{ns}}$ & $0.2077^{\mathrm{ns}}$ & $0.3998^{\mathrm{ns}}$
\end{tabular}

*Significant at a level of $5 \%$ of probability $(\mathrm{p}<0.05)$

${ }^{\text {ns }}$ Not significantly different

\section{Conclusion}

The study showed that the girth tape as a non-conventional method of estimation was effective to determine the live weight of goats as compared with the sophisticated weighing scale, which may not even be available. The dressing percentage of goats was WAD >Maradi>Sahel. It is thus important for goat farmers and stakeholders in marketing to understand the basis of dressing percentage determination because this information will be useful for the purpose of setting prices and calculating profitability.

\section{Acknowledgement}

The authors wish to express their appreciation to the management of the 
Assessment of conventional and non-conventional estimation of live weight, carcass characteristics and the dressing percentage of Nigerian breeds of goats

slaughter house, University of Ibadan for providing the fund for the purchase of the three breeds of goats used for the study.

\section{References}

Ahamefule, F. O., Ibeawuchi, J. A. and Ibe, S. N. 2005. Performance of African dwarf bucks fed pigeon pea cassava based diets. J. Anim. Vet. Adv. 4(12). 1010-1015.

Dhanda, J. S., Taylor, D .G. and Murray, P. J. 2003. Growth carcass and meat quality parameters of male goats: effects of genotype and live weight at slaughter. Small Ruminant Research, 50, 57-66.

Fasae, O. A., Adu, I. F., Aina, A. B. J. and Dipeolu, M. A. 2011. Effects of Different Dressing Methods on the Carcass Characteristics and Chemical Composition of Meat from Traditionally Managed West African dwarf Sheep. Academia

Fajemilehin, S. O. K. and Salako, A. E. 2008. Body measurement characteristics of the West African Dwarf (WAD) Goat in deciduous forest zone of Southwestern Nigeria. African Journal of Biotechnology Vol. 7 (14), pp. 2521-2526

Francisco de A. S. e Silva. 2016. ASSISTAT Version 7,7 en Statistical Assistance, Federal University of Campina Grande, Brazil.

Greenwood, P. L., May, T. J. and Finn, J. A. 1993. Development of objective methods for Marketing and promotion of goat meat (MRC/NSW Agriculture final report DAN 041. Sydney).

Kalc, A., Cividini, A. and Potocrick, $K$. 2012. Influence of sex and age at slaughter on growth performance and carcass traits of Boer kids. In: Proc. 20thSymp. Animal Science Days Kranyskagora, Slovenia. 281285.

Macdonald, T., Windsor, P., Rast, L. and Bush, R. 2009. Using Girth Measurements to Estimate the Live Weight of Cattle And Buffalo in Lao People's Democratic Republic (PDR). Faculty of Veterinary Science, The University of Sydney.

McGregor, B. 2012. The role of objective and subjective evaluation in the production and marketing of goats for meat, in Goat Meat Production and Quality, CAB International, Cambridge, Ma., pp.209-230.

Never, A. 2015. Some major factors affecting carcass composition in goats. Scientific Journal of Animal Science 4(7) 81-88

Sebsibe, A., Casey, N. H., Van, N. W. A., Tegegne, A. and Coertze, R. J. 2007. Growth performance and carcass characteristics of three Ethiopian goat breeds fed grainless diets varying in concentrate to roughage ratios. South. Afr. J. Anim. Sci.37(4), 221-232.

Slippers, S. C., Letty, B. A. and de Villiers, J. F. 2000. Prediction of the body weight of Nguni goats. South African J. of Anim. Sci. 30(1):127128.

Talton C. 2011. Meat Yield, Quality and Cuts. UGA Cooperative Extension. Georgia Organic Conference

Ukanwoko, A. I. and Onuoha, C. A. 2011. Growth performance and carcass characteristics of WAD goats fed oil palm leaf meal-cassava peel based diets. Cont. J. Anim. Vet. Res. 3(2), 1-6.

Received: $11^{\text {th }}$ September, 2016 Accepted: $17^{\text {th }}$ March, 2017 